\title{
USO DO ECOCARDIOGRAMA NA AVALIAÇÃO CARDÍACA DE BOVINOS
}

Milenna Karoline Fernandes Rodrigues ${ }^{1}$, Rosângela de Oliveira Alves Carvalho², Marcelo Borges dos Santos Júnior ${ }^{3}$, Fabiano José Ferreira de Sant'Ana ${ }^{4,}$ Paulo Henrique Jorge da Cunha ${ }^{5}$

'Doutoranda, Escola de Medicina Veterinária e Zootecnia da Universidade Federal de Goiás, Goiânia-Go, Brasil, milennavet@hotmail.com

2Doutora, Docente da Escola de Veterinária e Zootecnia, Universidade Federal de Goiás, Goiânia-Go, Brasil.

3Mestre, Escola de Medicina Veterinária e Zootecnia, Universidade Federal de Goiás, Goiânia-Go, Brasil.

${ }^{4}$ Doutor, Docente da Faculdade de Agronomia e Medicina Veterinária, Universidade de Brasília, Brasília-DF, Brasil.

${ }^{5}$ Doutor, Docente da Escola de Medicina Veterinária e Zootecnia, Universidade Federal de Goiás, Goiânia-Go, Brasil

Recebido em: 08/09/2015 - Aprovado em: 14/11/2015 - Publicado em: 01/12/2015 DOI: http://dx.doi.org/10.18677/Enciclopedia_Biosfera_2015_240

\begin{abstract}
RESUMO
As enfermidades cardíacas em bovinos repercutem em elevados prejuízos econômicos, por afetarem diretamente os índices de produção dos animais acometidos. O diagnóstico das cardiopatias pode ser complementado pelo uso de ferramentas auxiliares como o ecocardiograma. A ecocardiografia é um exame não invasivo com elevada aplicabilidade na clínica de bovinos, com capacidade de fornecer informações sobre a morfologia cardíaca e a função hemodinâmica. Devido à variada aplicabilidade desse exame na buiatria, objetivou-se com essa literatura, agrupar e discutir aspectos relacionados ao seu uso na clínica de bovinos, abordando os parâmetros de normalidade e os achados ecocardiográficos encontrados nas principais enfermidades do coração de bovinos.
\end{abstract}

PALAVRAS-CHAVE: cardiopatias, ruminantes, ultrassom.

\section{ECHOCARDIOGRAPHY IN CATTLE CLINIC}

\begin{abstract}
Heart disease in cattle are causes of high economic losses by rebound in animal production rates affected by these diseases, which can have the diagnosis facilitated through tools such as echocardiography. Echocardiography is a diagnostic test with high applicability in cattle clinic to diagnose cardiopathies obtaining information on cardiac morphology and hemodynamic function, non-invasively. Because of the wide applicability of this examination in Buiatrics aimed with this literature, group and discuss aspects related to its use in bovine practice, addressing the normal parameters and echocardiographic findings in major cardiopathies of the bovine species.
\end{abstract}

KEYWORDS: heart disease, ULTRASOUND, ruminants. 


\section{INTRODUÇÃO}

$\mathrm{Na}$ medicina veterinária a abordagem das enfermidades cardíacas ainda apresenta uma série de dificuldades que se intensificam na clínica de grandes animais. Neste contexto, muitos veterinários têm visto as doenças do coração por meio de uma mística injustificada, sendo algumas vezes diagnosticadas incorretamente (BONAGURA \& PIPERS, 1983; DARK, et al., 2000).

As cardiopatias dos bovinos têm gerado prejuízos econômicos por repercutirem nos índices de produção dos animais acometidos. As principais afecções desse grupo incluem as reticulopericardites traumáticas, as endocardites bacterianas, os linfomas e os defeitos congênitos. Dessa forma, uma boa técnica de exame e uma correta interpretação dos dados obtidos em procedimentos diagnósticos são determinantes para elucidar os casos precocemente, estabelecer tratamentos eficazes e viáveis e determinar o prognóstico acurado desses pacientes.

Apesar dos avanços de métodos de diagnósticos, na clínica de animais de grande porte, o exame cardiovascular ainda está limitado ao exame físico e à eletrocardiografia. Embora estes métodos tenham um valor considerável, eles fornecem poucas informações sobre a anatomia, as dimensões e a função cardíaca. Uma eficiente ferramenta de diagnóstico é o uso do ultrassom que permite uma avaliação anatômica de forma qualitativa, quantitativa e funcional do coração, de uma maneira não-invasiva e segura. (DARKE, 2000).

Devido à variada aplicabilidade da ecocardiografia na buiatria, essa revisão teve como objetivo agrupar e discutir aspectos relacionados ao seu uso na clínica de bovinos, abordando os parâmetros de normalidade e os achados ecocardiográficos encontrados nas principais cardiopatias bovinas.

\section{PRINCÍPIOS DA ECOCARDIOGRAFIA}

A ecocardiografia é a avaliação do coração e dos grandes vasos por meio do emprego do ultrassom, registrando os dados sobre a forma de ondas sonoras refletidas, as quais são denominadas de ecos (SOUZA, 2010). Esta avaliação permite a obtenção de informações sobre a morfologia cardíaca e a função hemodinâmica, de forma não invasiva (GOWDA et al., 2004).

O ultrassom é um som de elevada frequência $(20000 \mathrm{~Hz})$ que não é detectado pelo aparelho auditivo humano (SOUZA, 2010), o qual detecta sons na frequência de $50-12,000 \mathrm{~Hz}$. Esta alta freqüência do ultrassom permite focalizar e controlar a direção do feixe do som e sua reflexão por objetos pequenos na faixa submilimétricas.

O exame ecocardiográfico consiste no uso de um aparelho ultrassonográfico, o qual é composto por um transdutor que envia ondas sonoras e recebe os ecos; uma unidade de processamento central (CPU) que faz todos os cálculos necessários no exame e fornece energia para manutenção do sistema; um controlador de pulsos do transdutor que altera a amplitude, a frequência e a duração dos pulsos emitidos pelo transdutor; um monitor que exibe a imagem dos dados do ultrassom processados pela CPU; um teclado/cursor que permite introduzir os dados do paciente e fazer medições a partir do monitor; um disco para armazenar as imagens obtidas e de forma não obrigatória uma impressora para impressão das imagens (CASTRO, 2012).

Os vários tipos de transdutores são a fonte de som no diagnóstico ultrassonográfico (BOON, 2011). O formato do transdutor determina seu campo de visão, ao passo que a frequência das ondas sonoras emitidas determina a que profundidade as ondas sonoras vão penetrar e a resolução da imagem (CASTRO, 
2012). O ultrassom é produzido pela estimulação elétrica de um cristal piezoelétrico, localizado no interior do transdutor. Essa estimulação faz com que o cristal se expanda e contraia, produzindo uma série de ondas sonoras, que se propagam sob a forma de feixe, o qual é transmitido através dos tecidos (SOUZA, 2010). Desse modo, quando o ultrassom encontra uma estrutura, parte dele é refletido e retorna ao transdutor, causando uma oscilação do cristal que é transformada em voltagem e detectada pelo equipamento o qual exibirá a imagem em um monitor (OYAMA, 2004). A transmissão do ultrassom através dos tecidos ocorre numa velocidade relativamente constante de aproximadamente $1.540 \mathrm{~m} / \mathrm{s}$. Sendo assim, o aparelho de ultrassom pode calcular o tamanho e a distância entre o transdutor e as estruturas que refletem o som baseando-se no tempo gasto entre a sua emissão e 0 retorno dos ecos refletidos (SOUZA, 2010). A interação entre o ultrassom e o tecido consiste em onda de reflexão, de refração, de transmissão e de atenuação. As ondas que são refletidas de volta para o transdutor são detectadas e convertidas em sinais elétricos, que são amplificados e exibidos como vídeo em pixels de brilho variável (OYAMA, 2004).

A capacidade do ultrassom para distinguir pequenas estruturas do coração, durante o exame ecocardiográfico, é referida como resolução do sistema. A resolução axial é a capacidade de discernir entre dois objetos que se encontram paralelos à direção do feixe, sendo dependente da frequência e da duração da do sinal da ecografia. Em geral, os feixes com uma frequência mais alta e comprimento de onda mais curto têm uma maior resolução axial. Sendo assim, as ondas de ultrassom e ondas com frequências mais altas possuem maior resolução do que aquelas com menor frequencias. A atenuação refere-se à perda de energia da onda de ultrassom à medida que viaja através do meio de propagação. Logo, a atenuação é maior quando são utilizados feixes de ultrassom de alta frequência, de forma que a relação paradoxal entre resolução e a atenuação do feixe dá origem a uma das grandes limitações do exame de ultrassom, por restringir a avalição de estruturas mais profundas dentro do campo de visão, confrontando o examinador em decidir por aumentar a penetração do feixe comprometendo a resolução e vice-versa (OYAMA, 2004), sendo assim, o grau de penetração no tecido é inversamente proporcional à frequência do sinal.

Todos os transdutores possuem uma marca de referência. Essa marca pode ser um cume, uma luz, um ponto colorido ou um relevo no transdutor. A marca de referência serve para definir o plano no qual o feixe de som deixa o transdutor, gerando um setor bidimensional com largura e profundidade ao longo do diâmetro ou o comprimento da face do transdutor indicada por esta marca. A imagem setorial produzida no monitor possui um símbolo no canto superior direito ou esquerdo que corresponde para onde a marca de referência do transdutor está sendo dirigida, permitindo uma orientação das estruturas visualizadas no setor em relação a marca de referência (BOON, 2011).

\section{ECOGRAFIA BIDIMENSIONAL}

A ecocardiografia bidimensional, também conhecida como ecografia em tempo real, permite a avaliação de forma mais compreensiva da anatomia cardíaca e sua relação espacial (GOWDA et al., 2004). Neste modo, os transdutores emitem múltiplos feixes de som na forma de um setor ou fatia de torta, resultando em imagens em um plano de corte reconstituindo em duas dimensões as estruturas anatômicas do coração (SOUZA, 2010). Quando o feixe é emitido ao coração e se depara com tecidos moles o som volta para o transdutor aparecendo em branco no 
monitor, já quando o feixe é emitido sobre espaços cheios de líquidos como as câmaras cardíacas, a falta de densidade reflete o som e a área aparecerá em preto no monitor do ultrassom (BOON, 2011). Os planos de imagem serão produzidos a partir do eixo longitudinal ou eixo longo, a partir do eixo transversal ou eixo curto (DARKE, 2000). A avaliação dos planos ecocardiográficos permite uma observação qualitativa do coração: pericárdio e estruturas adjacentes; contratilidade; morfologia como as anormalidades valvulares, das paredes cardíacas e dos grandes vasos (SOUZA, 2010). Além disso, é possível realizar as análises quantitativas por meio das medidas das estruturas cardíacas e inferir sobre a função do coração por meio dos índices funcionais do miocárdio.

\section{MODO M OU MOVIMENTO}

A ecografia em modo $M$ foi a forma de ultrassom cardíaco descrita primariamente e relatada pela primeira vez como ferramenta clinicamente útil na Medicina Veterinária em 1977 (PIPERS, 1977). Em geral, o modo M (Figura 1) é obtido diretamente do modo bidimensional, empregando-se um feixe unidimensional de ultrassom que foca em uma porção muito pequena do coração, visualizando na imagem em movimento somente as estruturas associadas à posição do cursor (BOON, 2011). Assim, as características relacionadas com tal linha de som através do coração deslizam ao longo do monitor e mudam sua espessura ou posição à medida que o coração se contrai e relaxa. Como resultado, a imagem no modo $M$ apresenta a profundidade cardíaca no eixo Y e o tempo no eixo X (SOUZA, 2010; BOON 2011).

A imagem no modo $M$ pode ser comprimida ou expandida ao longo do eixo $X$, de forma que a velocidade de varredura irá controlar a rapidez que uma imagem se move pela tela. As velocidades de varredura são de 25, 50, e $100 \mathrm{~mm} / \mathrm{s}$. $\mathrm{Na}$ velocidade de $25 \mathrm{~mm} / \mathrm{s}$ muitos ciclos cardíacos são incluídos em um quadro, entretanto, na velocidade de varrimento de $100 \mathrm{~mm} / \mathrm{s}$, menos ciclos cardíacos são vistos por quadro (BOON, 2011). Portanto animais com baixas frequências cardícas necessitam de uma velocidade de varredura mais baixas.

O estudo da ecocardiografia em modo M é valioso para a quantificação do tamanho das câmaras cardíacas, espessura e movimentação das paredes, dimensões dos grandes vasos e movimentação das válvulas (DARKE, 2000), permitindo discernir entre estruturas pequenas e com movimento rápido, bem como relacionar este movimento. 


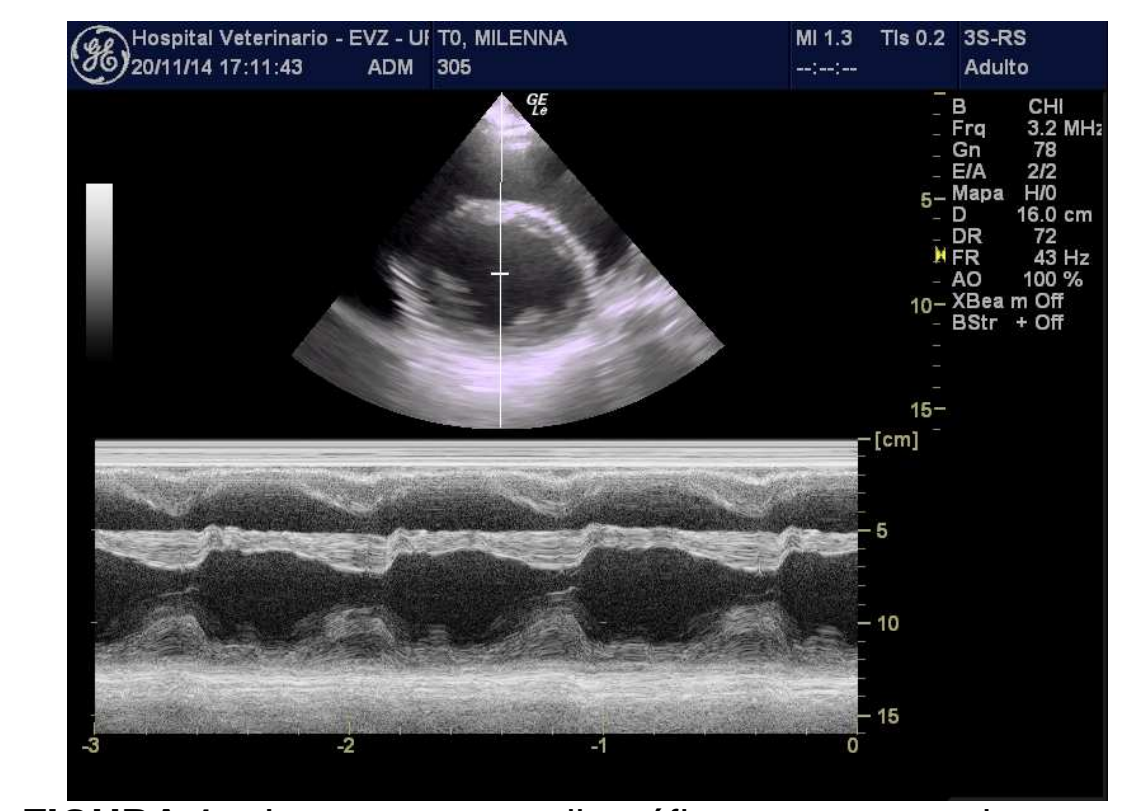

FIGURA 1 - Imagem ecocardiográfica representando o corte transversal dos ventrículos esquerdo e direito de coração de bovino. No modo bidimensional (imagem superior) é possível observar o posicionamento do cursor para obtenção da imagem em modo-M. Na imagem inferior podese observar a imagem em modo-M, representando as estruturas do ventrículo esquerdo e direito ao longo da linha de interrogação representadas versus o tempo.

\section{MODO DOPPLER}

O princípio Doppler (Figura 2) foi inicialmente aplicado para determinar a velocidade, a direção e a características do fluxo cardíaco e dos grandes vasos, baseado no efeito Doppler descrito por Christian Doppler (ZDRAVKOVIĆ et al., 2006). O efeito Doppler é o aumento da frequência do som quando a fonte sonora se movimenta em direção ao observador e à diminuição da frequência do som quando a fonte se afasta do observador (SOUZA, 2010). O recurso Doppler realiza a mensuração da velocidade do fluxo através da determinação na mudança de frequência de um feixe ultrassônico após a sua reflexão em elementos celulares sanguíneos em movimento. Com este recurso é possível determinar a direção de jatos regurgitantes, obstruções ao fluxo ou shunts, e ainda jatos turbulentos, permitindo a avaliação quantitativa da hemodinâmica e de índices de desempenho cardíaco (ANAVEKAR \& OH, 2009).

A ecografia Doppler pode ser feita no modo de onda contínua e de Doppler pulsátil. O Doppler de onda contínua refere-se à transmissão frequente do eco, por exemplo, o envio e o retorno dos ecos emitidos pelo movimento das hemácias são contínuos. Para isso o transdutor utilizado possui dois cristais, sendo um para enviar os sinais e o outro para receber o ultrassom que foi refletido (BOON, 2011). A principal vantagem do Doppler de onda contínua está em sua capacidade de quantificar a alta velocidade de fluxos anormais, por outro lado, não é possível determinar o ponto exato da alteração, mas apenas uma linha, ao longo da qual será 
feita a avaliação, fazendo com que a localização exata do sinal anormal não possa ser determinada (ANAVEKAR \& OH, 2009).

No modo Doppler de onda pulsada, um único cristal de ultrassom envia e recebe os feixes de som, alternadamente em forma de pulsos (BOON, 2011). A frequência de repetição do pulso (PRF) determina quando o próximo pulso será emitido (SOUZA, 2010). Já o limite de Nyquist é a velocidade máxima que pode ser medida pelo Doppler de onda pulsada e este limite é determinado pela fórmula: limite Nyquist= PRF/2. Se a frequência máxima é maior do que a frequência de Nyquist calculada, o espectro do fluxo apresentado pelo Doppler é cortado, e o deslocamento da frequência remanescente é gravado na parte superior ou inferior do lado oposto da linha de base (fenômeno aliasing). Portanto as velocidades mais altas podem ser gravadas sem aliasing usando o Doppler de onda contínua. Desse modo, é possível determinar alterações no fluxo simplesmente posicionando o cursor na localização desejada (ANAVEKAR \& OH, 2009).

A imagem de fluxo em cores é baseada em princípios do Doppler de onda pulsada, exibindo o fluxo de sangue intracavitario usando um mapa de cores de acordo com a velocidade, direção e extensão da turbulência. Ele usa vários locais de amostragem ao longo dos múltiplos feixes de ultrassom. Em cada ponto analizado, a frequência de deslocamento é medida, convertido para um formato digital de forma automática correlacionando com um esquema de cores predefinido, e exibido como o fluxo de cor sobreposta a imagens bidimensionais (ANAVEKAR \& OH, 2009).

O fluxo de sangue direcionado para o transdutor tem uma frequência positiva e é codificado por cores em tons de vermelho, já o fluxo de sangue direcionado para longe do transdutor tem desvio de frequência negativa e é codificado por cores em tons de azul (SOUZA, 2010). Cada cor tem várias sombras, e os tons mais leves dentro de cada cor primária são designados conforme as velocidades mais altas dentro do limite de Nyquist. Quando a velocidade de fluxo é maior do que o limite de Nyquist, o fenômeno aliasing ocorre e é descrito como reversão de cor e a cor volta repetidamente a cor oposta (ANAVEKAR \& OH, 2009). A turbulência é caracterizada pela presença de variância, que é a diferença entre a velocidade de escoamento e a velocidade individual do fluxo. A imagem de fluxo em cores tem um papel na quantificação do grau de insuficiência valvar ou cardíaca, assim como a quantificação de outras informações (DARKE, 2000). Atualmente, a maioria das avaliações hemodinâmicas intracardíacas necessárias para o manejo clínico de pacientes cardiopatas são realizados de forma não invasiva pelar ecografia bidimensional e modo Doppler (AMORY et al., 1992). 


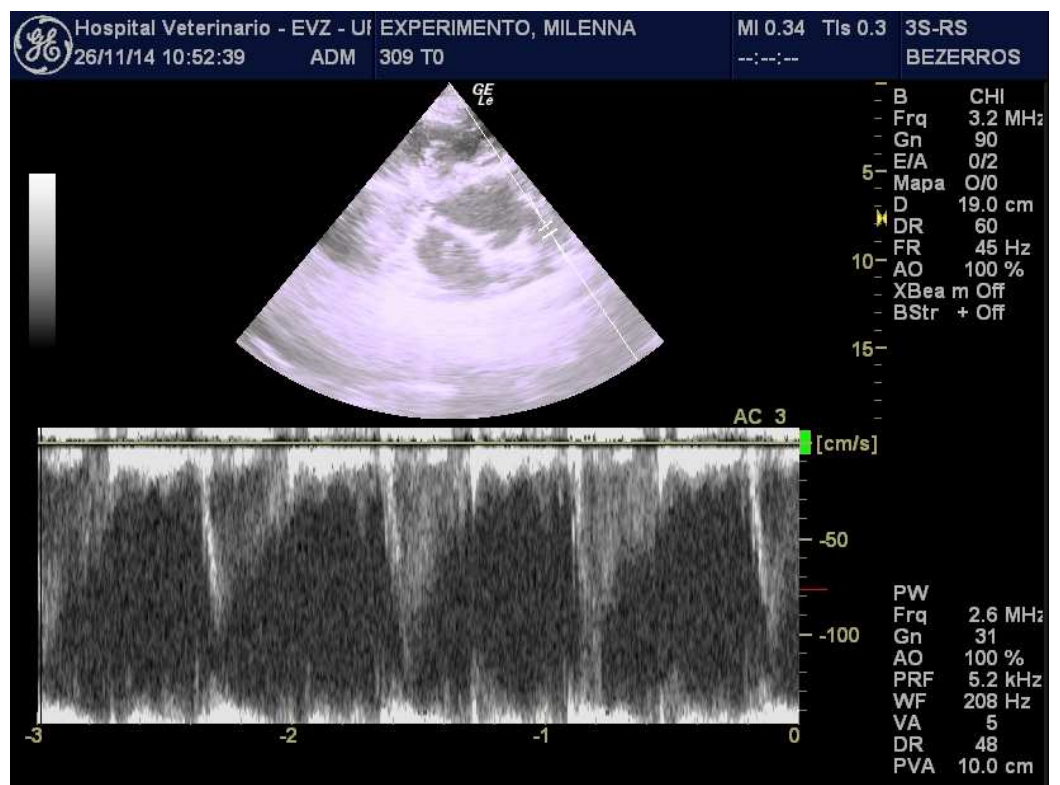

FIGURA 2 - Imagem ecocardiográfica do fluxo da válvula pulmonar de bovino. Na parte superior podese visualizar imagem bidimensional com posicionamento do cursor para obtenção do espectro em Doppler pulsado, cujo espectro é mostrado na imagem inferior.

\section{USO DA ECOCARDIOGRAFIA EM BOVINOS}

A ecocardiografia em bovinos pode ser realizada tanto à campo como no hospital (BUCZINSKI, 2009). A escolha do transdutor é de grande importância, uma vez que a profundidade de penetração e a resolução da imagem dependem da frequência escolhida. $O$ equipamento necessário consiste de uma sonda transdutora de baixa frequência $(2,5-3,5 \mathrm{MHz})$ para bovinos adultos, e uma sonda com uma frequência maior (3,75-5 MHz) para bezerros (AMORY et al., 1992). Apesar de os transdutores de frequência elevada serem indicados para pequenos animais, os mesmos também podem ser usados em animais de grande porte, a fim de melhorar a resolução de estruturas de campo próximo, como a válvula tricúspide, podendo obter maiores informações (BOON, 2011). O modo Doppler apresenta melhor qualidade quando é feito com transdutores de frequência mais baixa, permitindo obter maiores informações do fluxo avaliado, dessa forma, a maioria dos equipamentos mudam automaticamente para uma frequência menor quando o modo Doppler é usado (BUCZINSKI, 2009) .

O estreito espaço intercostal, a posição cranial do coração no peito do animal e a forma da sonda podem ser limitantes para completa avaliação de todos os pontos do coração. Uma pequena sonda do tipo "phasead array" (setorial cardíaca) é a preferida. No entanto, uma sonda setorial grande pode ser suficiente para permitir o diagnóstico das doenças mais comuns de bovinos como a endocardite bacteriana, a pericardite e os defeitos do septo ventricular (BUCZINSKI, 2008).

Nos bovinos, o ecocardiograma geralmente é realizado com o animal em posição quadrupedal (BUCZINSKI, 2009). Em bezerros, o exame também pode ser realizado com o animal contido em decúbito lateral direito sobre uma mesa que contenha uma abertura que permita a manipulação do transdutor, como as utilizadas para pequenos animais (BOON, 2011). 
A tricotomia da região que compreende do terceiro ao quinto espaço intercostal do lado direito e esquerdo deve ser realizada para minimizar os efeitos do ar sobre a transmissão do som (BUCZINSKI, 2009). A pele deverá ser lavada com água morna ou limpa com álcool e logo após, o gel de transmissão ultrassônico deve ser aplicado e reaplicado quando necessário. O uso de álcool antes de iniciar o exame ajuda a eliminar o ar e melhorar o contato com a pele quando o animal não pode ser depilado (BOON, 2011). O membro torácico respectivo ao lado em que está sendo realizado o exame deverá ser movido cranialmente ou suavemente abduzido para facilitar o contato entre o transdutor e o espaço intercostal (HALLOWELL et al., 2007).

O exame deve começar pelo lado direito do animal, avaliando todo o eixo longitudinal e o eixo transversal do coração e posteriormente completado no lado esquerdo, caso todo o coração não tenha sido avaliado a partir do lado direito (BUCZINSKI, 2009). Muitos estudos requerem um exame Doppler a partir do lado esquerdo do tórax (BOON, 2011).

Ecocardiografia paraesternal direita

O ecocardiograma realizado no lado direito do tórax permite a avaliação de três cortes do eixo longo (longitudinal) e um corte do eixo curto (transversal) do coração (BUCZINSKI, 2009), os quais serão descritos em seguida:

a) Visualização das quatro câmaras cardíacas

Quando o transdutor é aplicado paralelo ao quarto espaço intercostal na posição longitudinal é possível visualizar as quatro câmaras cardíacas (Figura 3), observando os átrios, ventrículos e o septo interventricular (BRAUN, et al., 2001). As trabéculas septomarginalis que ligam as paredes anterior e posterior do ventrículo direito são espessas podendo o quadro ser confundido com endocardite mural (BUCZINSKI, 2009).

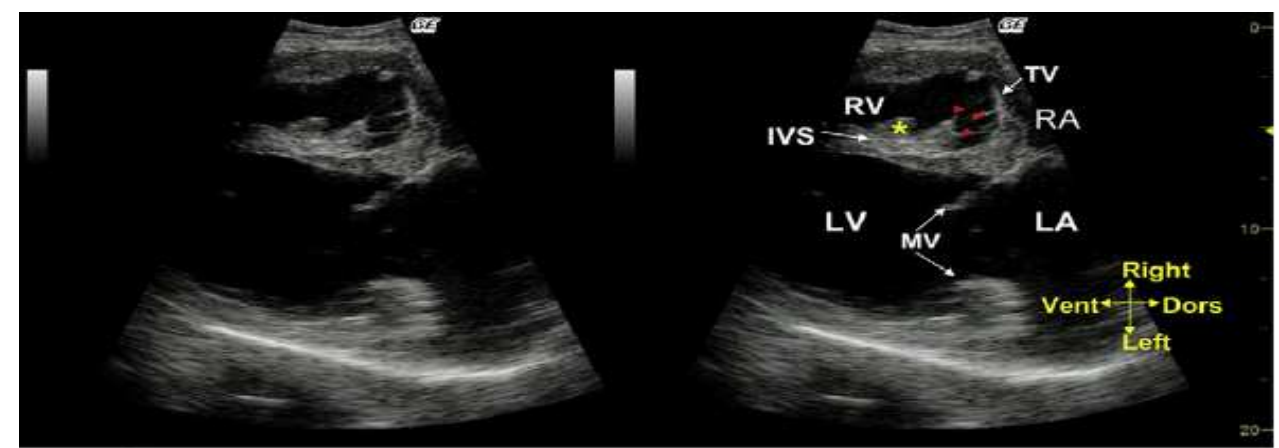

FIGURA 3 - Imagem ecocardiográfica paraesternal direita, vista das quatro câmaras do coração. A cordoalha tendínea da valva tricúspide é vista como linhas hiperecóicas (setas vermelhas). A banda moderadora $\left({ }^{*}\right)$ também é parcialmente observada emergindo da parede posterior do ventrículo direito. IVS (septo interventricular); LA (átrio esquerdo); MV (válvula mitral); RA (átrio direito); RV (ventrículo direito), LV (ventrículo esquerdo); TV (válvula tricúspide); Dors (base); Vent (ápice); Right (direito); Left (esquerdo).

Fonte: BUCZINSKI, 2009 
b) Saída do ventrículo esquerdo

Quando o transdutor é posicionado ainda no quarto espaço intercostal, ligeiramente mais cranial com uma leve rotação no sentido horário, pode-se observar a via de saída do ventrículo esquerdo (LVOT) juntamente com a imagem de todo o ventrículo, o átrio esquerdo, a válvula aórtica e da raiz da aorta, além do ventrículo direito e do átrio direito (Figura 4).

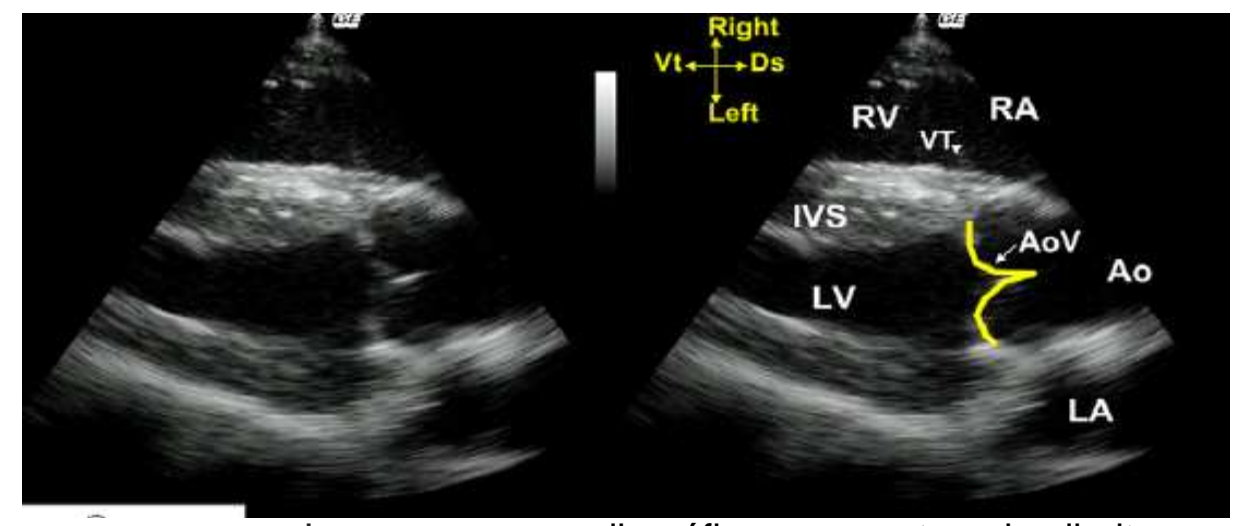

FIGURA 4 - Imagem ecocardiográfica paraesternal direita, corte longitudinal do ventrículo esquerdo. A válvula aórtica também é observada e representada como uma linha amarela. IVS (septo interventricular); LA (átrio esquerdo); LV (ventrículo esquerdo); RA (átrio direito); RV (ventrículo direito), VT (válvula tricúspide), Dors (base); Vent (ápice); Ao Fonte: BUCZINSKI, 2009 (aorta); AoV (valva aórtica); Right (direito); Left (esquerdo).

c) Saída do ventrículo direito

Uma ligeira rotação do transdutor no sentido horário no quarto espaço intercostal ou a presença do mesmo no terceiro espaço intercostal, 8 a $10 \mathrm{~cm}$ ao nível dorsal do olécrano, permite a visualização da via de saída do ventrículo direito (VSVD) (Figura 5), observando-se o ventrículo direito, o átrio direito, a válvula pulmonar e o tronco pulmonar (BRAUN et al., 2001; BUCZINSKI, 2009).

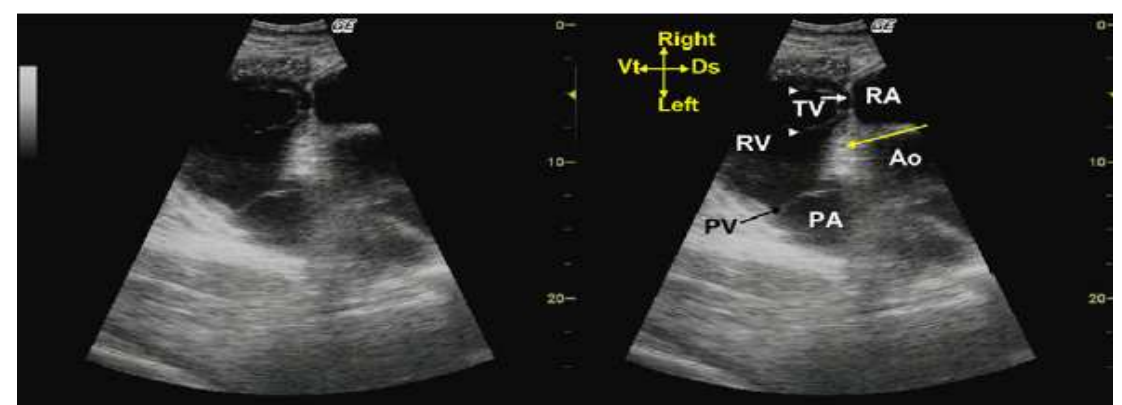

FIGURA 5 - Imagem ecocardiográfica paraesternal direita, corte longitudinal, saída do ventrículo direito. A seta amarela representa a artéria coronária, observada entre a aorta e o ventrículo direito. A cordoalha tendínea da valva tricúspide também é observada (seta branca). Ao (aorta); Ds (dorsal), PA (artéria pulmonar); PV (válvula pulmonar), RA (átrio direito); RV (ventrículo direito); TV (válvula tricúspide), Vt (ventral); Right (direito); Left (esquerdo).

Fonte: BUCZINSKI, 2009 
d) Corte transversal dos ventrículos pelo lado direito

A vista do eixo curto do coração (corte transversal) (Figura 6) é obtida colocando o transdutor perpendicular às nervuras no quarto espaço intercostal para observar uma seção transversal de ambos os ventrículos, observando o ventrículo direito, o septo interventricular, o ventrículo esquerdo e o músculo papilar (Braun, Schweizer et al. 2001). A vista do eixo curto pode ser difícil de obter, devido à interferência causada pela superfície pleural (BUCZINSKI, 2009).

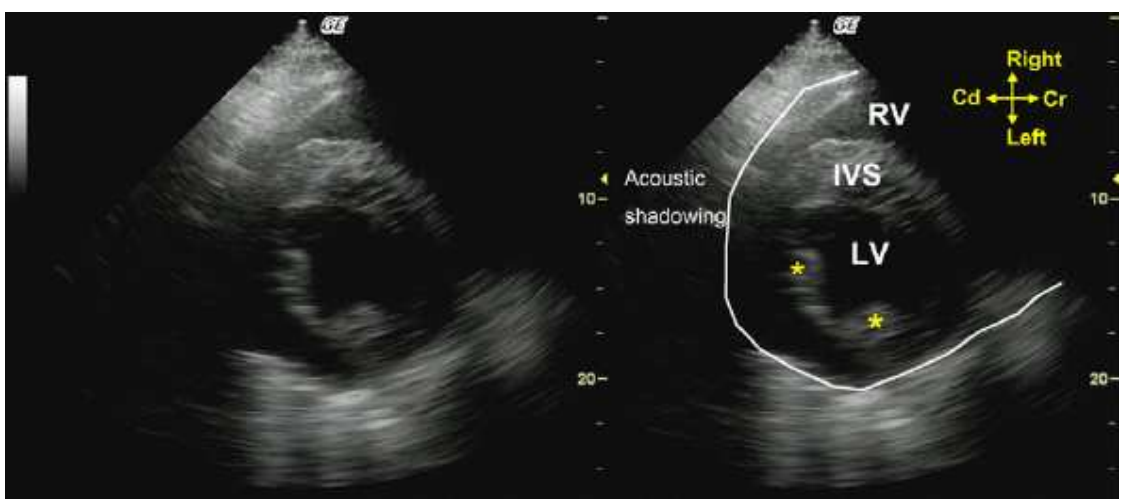

FIGURA 6 - Imagem ecocardiográfica paraesternal direita, corte transversal dos ventrículos. Os músculos papilares do ventrículo esquerdo são observados $\left({ }^{*}\right)$, revelando a forma de cogumelo do lúmen do ventrículo esquerdo. Cd (caudal), Cr (cranial), IVS (septo interventricular); LV (ventrículo esquerdo), $\mathrm{RV}$ (ventrículo direito).

Fonte: BUCZINSKI, 2009

Ecocardiografia paraesternal esquerda

A ecocardiografia do lado esquerdo é especialmente útil quando há suspeita de alguma alteração no lado esquerdo do coração (Buczinski 2009).

a) Visualização das quatro câmaras pelo lado esquerdo

O corte caudal do eixo longo do coração (Figura 7) é obtido com o transdutor colocado no quarto ou quinto espaço intercostal dorsalmente de 5 a 10 $\mathrm{cm}$ ao nível do olécrano dirigido ligeiramente caudodorsal (BUCZINSKI, 2009). Adjacente à parede do tórax observa-se o ventrículo esquerdo, a válvula mitral e uma pequena parte do átrio esquerdo, além disso, medialmente observa-se o septo interventricular, o ventrículo direito, a válvula tricúspide e o átrio direito (BRAUN et al. 2001). 


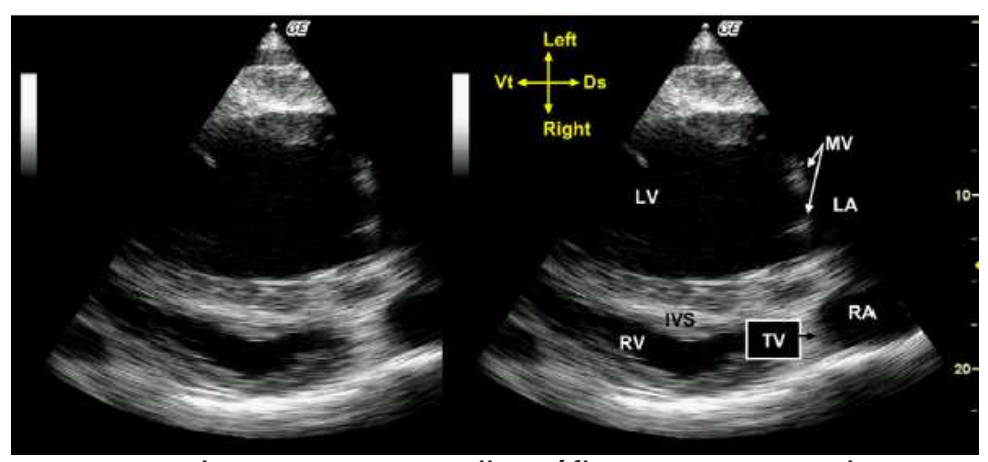

FIGURA 7 - Imagem ecocardiográfica paraesternal esquerda, corte longitudinal das quatro câaras cardíacas. Neste corte as quatro câmaras cardíacas são observada, bem como as válvulas atrioventriculares. Ds (base), IVS (septo interventricular), LA (átrio esquerdo), LV (ventrículo esquerdo), MV (mitral válvula), RA (átrio direito), RV (ventrículo direito), TV (válvula tricúspide), Vt (ápice); Right (direito);

Fonte: BUCZINSKI, 2009 Left (esquerdo).

b) Saída do ventrículo esquerdo

A visualização da saída do ventrículo esquerdo (Figura 8) pelo corte longitudinal é feita com o transdutor colocado na mesma posição citada anteriormente, sendo inclinado cranialmente e girado ligeiramente para a esquerda (BUCZINSKI, 2009). Nesta imagem é observdo o ventrículo esquerdo, a válvula aórtica e aorta ascendente, o septo interventricular, o ventrículo direito, a válvula tricúspide e o átrio direito (BRAUN et al. 2001).

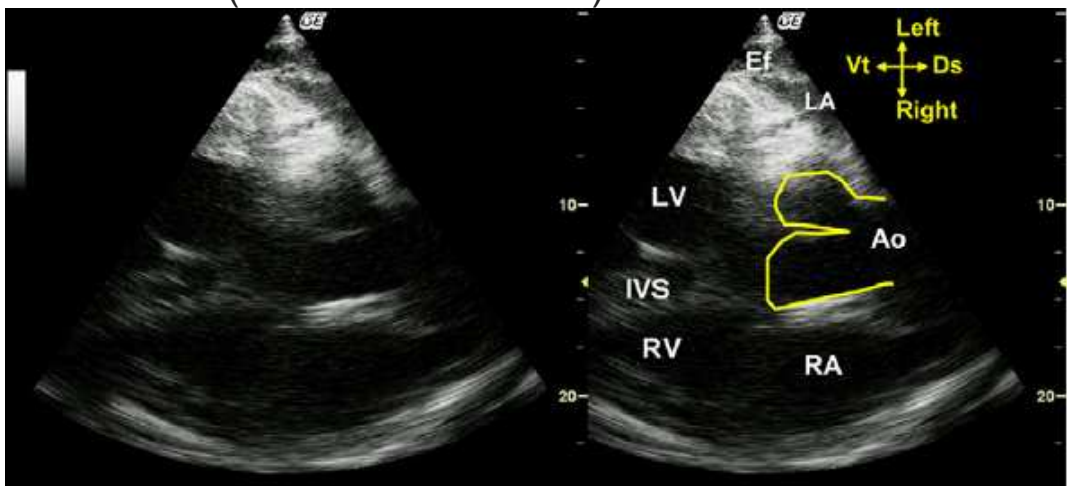

FIGURA 8 - Imagem ecocardiográfica paraesternal esquerda, corte longitudinal d saída ventrículo esquerdo. $O$ átrio esquerdo, ventrículo esquerdo e aorta são observados. A visão transversal da válvula aórtica é reconhecida como uma linha ecoica. Uma pequena quantidade de derrame pleural também é vista. Ao (aorta), Ds (base), Ef (derrame pleural), IVS (septo interventricular), LA (átrio esquerdo), LV (ventrículo esquerdo), RA (átrio direito), RV (ventrículo direito), Vt (ápice); Right (direito); Left (esquerdo).

Fonte: BUCZINSKI, 2009 
c) Visualização cranial do eixo longitudinal

A visualização cranial do eixo longitudinal pelo lado esquerdo (FIGURA 9) permite observar o fluxo de saída do ventrículo direito que consiste na artéria pulmonar e na válvula pulmonar. Para isso, o transdutor deve estar paralelo às nervuras no terceiro espaço intercostal esquerdo, de 3 a $6 \mathrm{~cm}$ dorsal ao nível do olécrano e ligeiramente craniodorsal. As estruturas visualizadas são a artéria pulmonar e a válvula pulmonar, o ventrículo direito, a válvula tricúspide e átrio direito (BRAUN et al. 2001).

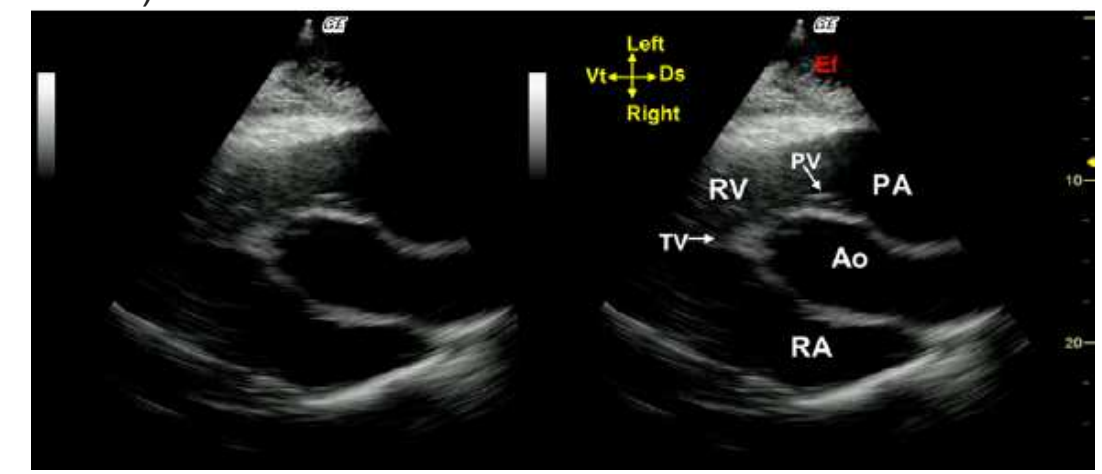

FIGURA 9 - Imagem ecocardiográfica paraesternal esquerda, visualização cranial do eixo longitudinal. $\mathrm{O}$ átrio esquerdo, ventrículo esquerdo e aorta são observados. A visão transversal da válvula aórtica é reconhecida como uma linha ecoica. A pequena quantidade de derrame pleural também é vista. Ao (aorta), Ds (base); Ef (derrame pleural); TV (válvula tricúspide); RA (átrio direito), RV (ventrículo direito), PA (artéria pulmonar), PV (válvula pulmonar), Vt (ápice).

Fonte: BUCZINSKI, 2009

\section{PARÂMETROS QUANTITATIVOS DE NORMALIDADE PARA BOVINOS}

Alguns estudos foram realizados com objetivo de estabelecer os valores normais para as medidas de estruturas cardíacas, visto que há poucos estudos quantitativos do coração. Para que essas dimensões sejam precisas, as imagens devem ser formadas a partir de planos corretamente orientados (HALLOWELL et al. 2007).

Hallowell et al. (2007) realizaram medições ecocardiográficas em vacas adultas vazias da raça Jersey e Holandesa (Tabela 1). Neste estudo, as vacas Jersey apresentaram valores próximos aos da raça Holandesa, contudo levando em consideração a relação com o peso do animal, estas vacas apresentavam valores maiores. Segundo estes autores a técnica para obtenção das imagens ecocardiográficas é relativamente simples, apesar de requerer um pouco de força física para obtenção das imagens, principalmente os cortes transversais. 
TABELA 1 - Medidas ecocardiográficas normais de vacas Jersey e Holandesa. $\mathrm{N}$ (número de medidas utilizadas na análise); PA (diâmetro da artéria pulmonar em diástole); Ao (diâmetro da aorta em diástole); PA:Ao (proporção entre PA e Ao); Ao-cs (diâmetro do corte transversal da aorta na diástole), LAD (diâmetro do átrio esquerdo na sístole); ET (tempo de ejeção); PEP (período de pré-ejeção); EPSS (ponto de separação entre os septos); RVDd (diâmetro ventricular direito na diástole); RVDs (diâmetro do ventrículo direito na sístole); RVDs (diâmetro do septo interventricular na diastole); IVSd (diâmetro do septo, interventricular na sístole); DdVE, diâmetro do ventrículo esquerdo na diástole; LVDd (diâmetro do ventrículo esquerdo na sístole); FWD (diâmetro da parede do ventrículo esquerdo na diástole); FWs (diâmetro de parede do ventrículo esquerdo na sístole); FS (fração de encurtamento); LVEF (fração de ejeção do ventrículo esquerdo); HR (freqüência cardíaca); VTI (tempo de velocidade integral); CO (débito cardíaco); Cl (índice cardíaco).

\begin{tabular}{lcccc}
\hline Parâmetro & Jersey & Holandesa \\
\hline & $\mathbf{N}$ & Média & $\mathbf{N}$ & Média \\
PA $(\mathrm{cm})^{*}$ & 10 & $4,2 \pm 0,27$ & 12 & $5,5 \pm 0,8$ \\
Ao $(\mathrm{cm})^{*}$ & 10 & $5 \pm 0,26$ & 12 & $6,4 \pm 0,62$ \\
PA:Ao & 10 & $0,85 \pm 0,07$ & 12 & $0,86 \pm 0,09$ \\
AoS $(\mathrm{cm})^{*}$ & 10 & $5,7 \pm 0,34$ & 12 & $7,94 \pm 0,56$ \\
Ao-cs $(\mathrm{cm})^{*}$ & 10 & $5,15 \pm 0,31$ & 12 & $7,05 \pm 1,17$ \\
LAD $(\mathrm{cm})^{*}$ & 10 & $10,9 \pm 0,5$ & 12 & $12 \pm 1,2$ \\
ET $(\mathrm{ms})$ & 10 & $0,26 \pm 0,08$ & 12 & $0,21 \pm 0,1$ \\
PEP $(\mathrm{ms})$ & 10 & $0,07 \pm 0,03$ & 12 & $0,09 \pm 0,1$ \\
EPSS $(\mathrm{cm})$ & 9 & $0,45 \pm 0,48$ & 11 & $0,62 \pm 0,23$ \\
RVDd $(\mathrm{cm}) \mathrm{p}$ & 10 & $2,45 \pm 0,53$ & 12 & $2,27 \pm 0,76$ \\
RVDs $(\mathrm{cm}) \mathrm{p}$ & 10 & $1,32 \pm 0,63$ & 12 & $1,14 \pm 0,43$ \\
IVSd $(\mathrm{cm})$ & 8 & $2 \pm 0,4$ & 11 & $2,2 \pm 0,51$ \\
IVSs $(\mathrm{cm}) \mathrm{p}$ & 8 & $3,6 \pm 0,5$ & 11 & $3,4 \pm 0,5$ \\
LVDd $(\mathrm{cm})^{*}$ & 8 & $7,7 \pm 0,7$ & 11 & $8,7 \pm 1,0$ \\
LVDs $(\mathrm{cm}) \mathrm{p}$ & 8 & $4,2 \pm 0,53$ & 11 & $4,2 \pm 0,8$ \\
FWd $(\mathrm{cm})$ & 8 & $1,2 \pm 0,3$ & 11 & $1,5 \pm 0,4$ \\
FWs $(\mathrm{cm})$ & 8 & $1,5 \pm 0,5$ & 11 & $1,4 \pm 0,5$ \\
FS $(\%)$ & 8 & $44,7 \pm 8,3$ & 11 & $46,5 \pm 9,5$ \\
LVEF & 8 & $0,85 \pm 0,09$ & 11 & $0,79 \pm 0,15$ \\
HR $(\mathrm{bpm})$ & 10 & $71,0 \pm 6,0$ & 11 & $72,3 \pm 4,5$ \\
VTI $(\mathrm{cm})$ & 10 & $30,4 \pm 3,41$ & & \\
CO $(\mathrm{L} / \mathrm{min})$ & 10 & $56,5 \pm 8,44$ & & \\
Cl $(\mathrm{ml} / \mathrm{kg} / \mathrm{min})$ & 10 & $123 \pm 5,7$ & & \\
A & 8 tado de HALLOWELL & &
\end{tabular}

Adaptado de HALLOWELL et al., 2007

As medidas ecocardiográficas em vacas Holandesas secas e em lactação classificadas em alta e baixa produção também foram estudadas (Tabela 2), sendo possível verificar que o nível de produção durante a lactação tem alguns efeitos sobre os parâmetros ecocardiográficos nestes animais (ZARIFIT et al., 2012). O estudo demostrou que a frequência cardíaca das vacas de alta produção no início da lactação foi significativamente maior do que no período seco. Além disso, o diâmetro 
ventricular direito na diástole, o volume ventricular direito na diástole e volume sistólico foram maiores em vacas de alta produção durante o início da lactação quando comparados com vacas de baixa produção, indicando uma função cardíaca mais eficaz nestes animais.

As medidas ecocardiográficas também foram estabelecidas para bezerros com idade entre oito e 28 dias (Tabela 2) observando-se uma tendência dos bezerros em apresentar menor diâmetro da câmara cardíaca esquerda, apesar de mantidas as relações de espessura de parede e índices funcionais do miocárdio (MICHIMA et al., 2007).

TABELA 2 - Valores ecocardiográficos (média \pm desvio-padrão da média) obtidos pela janela paraesternal direita, em bezerros da raça Holandesa. a variação, $b \mathrm{n}=22, \mathrm{c} n=23, \mathrm{~d} n=21$; $d$ : mensurações em diástole; s: mensurações em sístole; $A D$ : átrio direito; $A E$ : átrio esquerdo; $A o$ : diâmetro aórtico em diástole; DIVD: diâmetro interno do ventrículo direito; DIVE: diâmetro interno do ventrículo esquerdo; PLVE: parede livre do ventrículo esquerdo; SIV: septo interventricular.

\begin{tabular}{ll}
\hline Parâmetros & Valores \\
\hline Idade (dias) & $8-28 \mathrm{a}$ \\
Peso $(\mathrm{kg}) \mathrm{b}$ & $40,34 \pm 1,37$ \\
ADs $(\mathrm{cm}) \mathrm{c}$ & $2,97 \pm 0,12$ \\
AEs $(\mathrm{cm}) \mathrm{d}$ & $4,11 \pm 0,21$ \\
DIVDd $(\mathrm{cm})$ & $2,055 \pm 0,13$ \\
DIVDs $(\mathrm{cm})$ & $1,59 \pm 0,13$ \\
SIVd $(\mathrm{cm})$ & $1,24 \pm 0,04$ \\
SIVs $(\mathrm{cm})$ & $1,62 \pm 0,06$ \\
DIVEd $(\mathrm{cm})$ & $3,91 \pm 0,09$ \\
DIVEs $(\mathrm{cm})$ & $2,52 \pm 0,13$ \\
PLVEd $(\mathrm{cm})$ & $0,92 \pm 0,04$ \\
PLVEs $(\mathrm{cm})$ & $1,50 \pm 0,05$ \\
Ao $(\mathrm{cm})$ & $2,52 \pm 0,05$ \\
\hline
\end{tabular}

Adaptado de MICHIMA et al., 2007

Estudos ecocardiográficos também foram realizados comparando bezerros clonados e bezerros produzidos por transferência de embriões até 24 horas de vida, podendo observar que os parâmetros obtidos nos bezerros clonados são numericamente maiores que o grupo controle, provavelmente em decorrência do elevado perímetro torácico apresentado pelos clones. (BATCHELDER al. 2005).

TABELA 3 - Características ecocardiográficas de bezerros clonados. VE (ventrículo esquerdo - sístole); VD (ventrículo direito - sístole)

\begin{tabular}{lcccc}
\hline Parâmetro & \multicolumn{2}{c}{ Clones } & \multicolumn{2}{c}{ Controle } \\
\hline & Média & Variação & Média & Variação \\
Parede livre VE $(\mathrm{cm})$ & 1,88 & $1,39-2,48$ & 1,55 & $0,93-1,65$ \\
Parede livre VD (cm) & 1,48 & $1,31-1,61$ & 1,25 & $1,12-1,28$ \\
Diâmetro de VD (cm) & 0,86 & $0,35-1,06$ & 1,27 & $0,65-1,82$ \\
Diâmetro da aorta $(\mathrm{cm})$ & 2,43 & $1,82-2,66$ & 2,65 & $1,88-2,85$ \\
Diâmetro da artéria pulmonar (cm) & 2,56 & $2,14-2,9$ & 2,3 & $2,03-2,48$ \\
Velocidade do fluxo na aorta (m/s) & 1,32 & $1,20-1,49$ & 1,02 & $0,96-1,10$ \\
\hline Adaptado de Batchelder et al., 2006 & & & &
\end{tabular}


Outras avaliações com bezerros Nelore clonados foram feitas comparando suas medidas ecocardiográficas com as de bezerros originados de monta natural (MN) ou inseminação artificial (IA) (Pogliani 2010). Segundo este estudo os valores ecocardiográficos obtidos para o grupo de clones não devem ser usados como referência para bezerros Nelore originados a partir de IAou MN em função de os bezerros clonados serem bem mais pesados que os do outro grupo. Além disso, pode-se verificar que a presença de fluxo através do forame oval foi detectado pelo modo Doppler colorido em bezerros clonados em até 10 dias de vida enquanto que em bezerros originados através de IA ou MN em até sete dias de vida.

\section{APLICAÇÕES DA ECOCARDIOGRAFIA NA CLÍNICA DE BOVINOS}

A ecocardiografia é uma ferramenta útil no diagnóstico de enfermidades cardíacas, complementando outros meios de diagnósticos como exame clínico, bioquímica sérica, hemograma, hemocultura, pericardiocentese e eletrocardiograma. As enfermidades cardíacas mais comuns em bovinos são a endocardite valvular, a pericardite e os defeitos de septo ventricular (BEXIGA et al., 2008). Além disso, há relatos do uso da ecocardiografia no diagnóstico de intoxicações (BRIHOUM et al. 2010, PEIXOTO et al. 2010, BRIHOUM et al., 2011)

Os achados ecocardiográficos em casos de suspeita de cardiopatia incluem achados específicos e inespecíficos que aparecem em virtude da insuficiência cardíaca congestiva (como o derrame pleural e compressão do pulmão) (BRAUN, 2009).

Este exame pode ser realizado facilmente em condições de campo, apresentando boa sensibilidade e especificidade mesmo quando a doença ainda não tenha evoluído para insuficiência cardíaca (BRAUN et al., 2008). Contudo, a utilidade do ecocardiograma é limitada ao diagnóstico das cardiopatías e ainda não existem parâmetros suficientes para determinação prognóstica nos casos de bovinos (BUCZINSKI et al., 2010). Pesquisas realizadas com objetivo de definir medidas ecocardiográficas dos tamanhos e defeitos do septo ventricular não apresentaram valores para o prognóstico nestas enfermidades em bovinos (BUCZINSKI et al., 2006), necessitando de mais estudos com o objetivo de encontrar parâmetros prognósticos nesta espécie (BUCZINSKI et al. 2010).

\section{a) Doenças pericárdicas}

O pericádio protege o coração e influencia a função diastólica do ventrículo quando o espaço pericárdico está ocupado por líquido (pericardite) ou massas (DARKE, 2000). A pericardite é o distúrbio mais comum do pericárdio em bovinos, com diferentes causas, mas achados clínicos semelhantes (BEXIGA et al., 2008).

O derrame pericárdico secundário à reticulopericardite traumática é comum, apresentando efusão purulenta com diferentes quantidades de fibrina. Nestes casos o derrame será obervado na ecocardiografia com aspecto hiperecóico (BUCZINSKI, 2008), com coágulos de fibrina ecoicos (SCHWEIZER et al., 2003) e visualização da camada do pericárdio que não é observada em animais saudáveis, apresentando forma de uma membrana hiperecóica grossa em volta do coração (BUCZINSKI, 2008). Pontos hiperecoicos associados a artefato de reverberação (produção de ecos falsos causados por estruturas refletoras no caminho do som) também podem ser observados quando há presença de gás livre em casos de efusão pericárdica séptica (BUCZINSKI, 2009). 
Outra enfermidade que causa derrame pericárdico é a pericardite hemorrágica idiopática (PHI) que foi mencionada como uma causa incomum de derrame pericárdico, possuindo bom prognóstico para bovinos (FIRSHMAN et al., 2006). Os achados ecocardiográficos em casos de PHI consistem em derrame pericárdico que varia de anecóico (Figura 10) a hipoecoico com ou sem coágulos ecogênicos de fibrina (JESTY et al. 2005). Como a IHP e a pericardite séptica podem ter os mesmos aspectos ultrassonográficos, o diagnóstico definitivo sobre a origem do derrame pericárdico ainda precisa ser confirmado pela pericardiocentese e exame do fluido pericárdico (FIRSHMAN et al. 2006). Nestes casos, além do ecocardiograma ser útil para a confirmação da suspeita de derrame pericárdico, poderá também determinar o impacto desse derrame sobre as câmaras ou a função cardíaca, além de permitir uma escolha do local ideal para a pericardiocentese (BUCZINSKI, 2009).

O derrame pericárdico normalmente comprime o ventrículo e o átrio direito, juntamente com o ventrículo esquerdo (DARKE, 2000). Essa compressão é visível na ecocardiografia durante a diástole cardíaca pela medição das dimensões das câmaras cardíacas (BUCZINSKI, 2009). O aumento da pressão do pericárdio reduz secundariamente o volume final da diastóle ventricular, levando a diminuição na pré-carga do coração e um débito cardíaco parcialmente compensado pelo aumento da frequência cardíaca (LITTLE \& FREEMAN, 2006). Os depósitos ecogênicos de fibrina podem também ser um fator limitante para a diástole ventricular.

O derrame pericárdico anecóico também pode ser observado em outras doenças como nas neoplasias cardíacas e não cardíacas, hipoproteinemia, insuficiência cardíaca direita. (WORTH \& REEF, 1998). Mais estudos sobre o padrão ecocardiográfico do derrame pericárdico em bovinos devem ser realizados afim de fornecer maiores informações sobre o quadro, como o prognóstico dessas enfermidades em bovinos (BUCZINSKI, 2009).

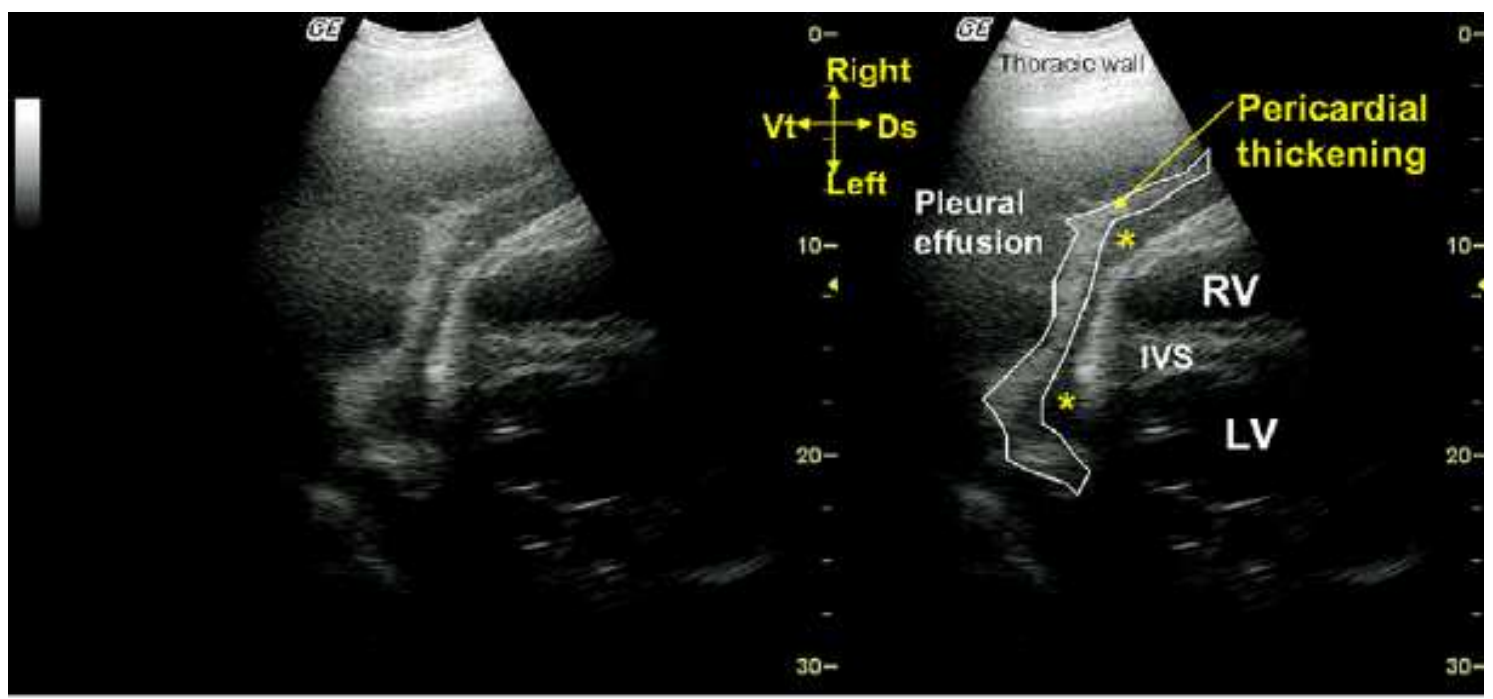

FIGURA 10 - Corte longitudinal do coração de um bovino com derrame pericárdio anecóico A pericardite hemorrágica idiopática foi diagnosticado após análise do líquido pericárdico. Ds (dorsal), IVS ( septo interventricular), RV (ventrículo direito), Vt (ventral), Right (direito), Left (esquerdo).

Fonte: BUCZINSKI, 2009 
b) Endocardites

A endocardite bacteriana é a doença mais comum do endocárdio de bovino e consiste em infecção bacteriana das valvas cardíacas e raramente do endocárdio mural (DARKE, 2000), levando ao espessamento do endocárdio e à insuficiência valvular. Os animais que possuem esta enfermidade podem apresentar sopro como sinal clínico que leva à suspeita de endocardite valvular (BRAUN et al., 2008).

No exame ecocardiográfico é possivel observar o espessamento valvular com uma confiabilidade que variou em estudos realizados de 75 a $100 \%$ dos casos (HEALY, 1996; BUCZINSKI et al., 2010), de forma que a válvula mais frequentemente afetada é a tricúspide, sendo mais facilmente diagnosticada por este exame (HEALY, 1996).

As alterações observadas durante a ultrassonografia cardíaca de bovino com endocardite incluem o espessamento irregular do folheto valvular afectado ou do endocárdio mural que pode apresentar aspecto vegetativo ou uma característica felpuda (SCHWEIZEr et al. 2003) (Figura 11). O endocárdio acometido apresenta-se mais ecogênico, contudo, espessamentos inferiores a $5 \mathrm{~mm}$ podem não ser observados (YAMAGA \& TOO, 1987). Além de diagnosticar a válvula acometida, a ecocardiografia também permite avaliar o impacto da doença sobre a morfologia cardíaca como nos casos de dilatação do átrio e do ventrículo direito secundária a endocardite da válvula tricúspide (BUCZINSKI, 2008).

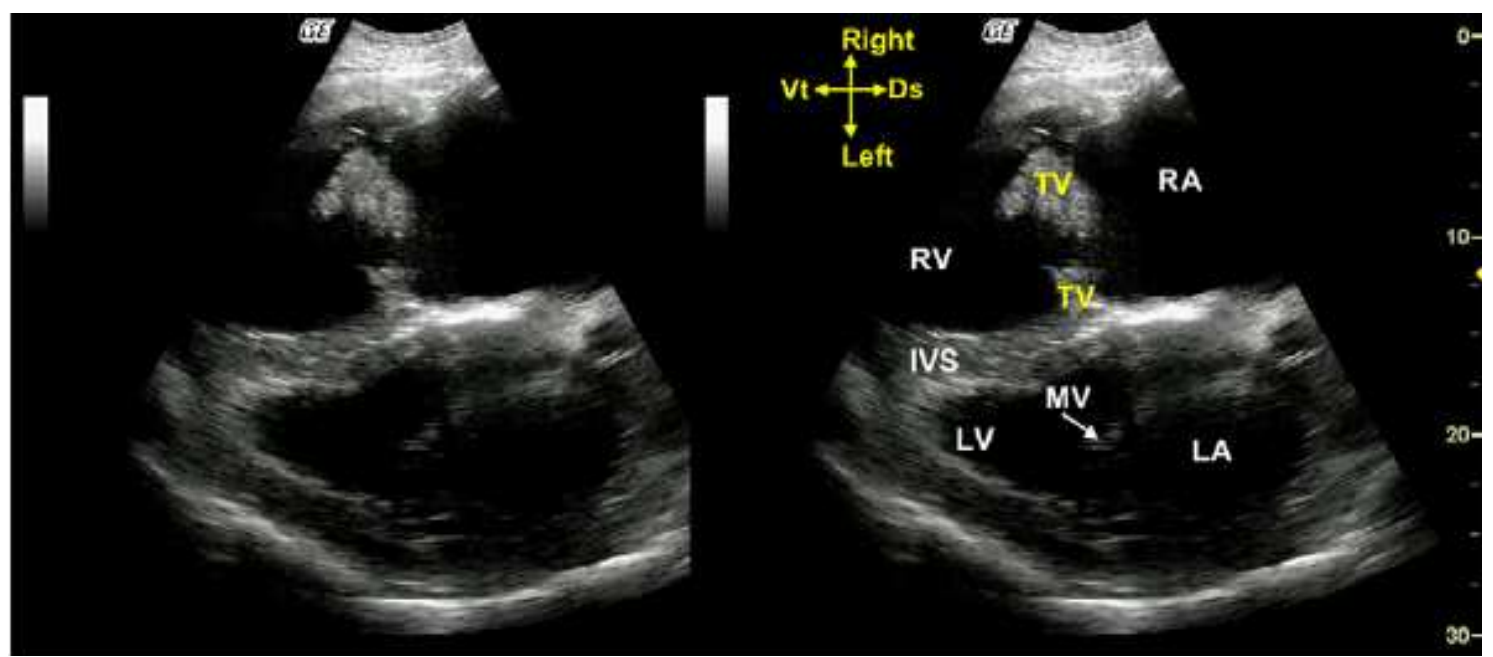

FIGURA 11 - Corte longitudinal das quatro câmara cardíacas pelo lado direito de uma vaca com endocardite na válvula tricúspide. A válvula tricúspide está marcadamente espessa. A regurgitação pela insuficiência valvular da tricúspide levou a dilatação secundária do átrio direito. Ds (base), IVS (septo interventricular), LA (átrio esquerdo), LV (ventrículo esquerdo), MV (válvula mitral), RA (átrio direito), RV (ventrículo direito), TV (válvula tricúspide), Vt (ápice), Right (direito), Left (esquerdo).

Fonte: BUCZINSKI, 2009

c) Neoplasias cardíacas

A neoplasia cardíaca mais comum em bovinos é o linfoma decorrente da infecção pelo retrovírus da leucose enzoótica bovina (REEF, 2002). A infiltração da base do coração, especialmente do átrio direito e o derrame pericárdio são os principais achados observados nesta neoplasia (BUCZINSKI et al., 2010). ENCICLOPÉDIA BIOSFERA, Centro Científico Conhecer - Goiânia, v.11 n.22; p.2765 2015 
Ecocardiograficamente os animais com linfoma cardíaco apresentam derrame pericárdio anecoico (VAN BIERVLIET et al., 2006) com um pouco de fibrina hiperecoica (YAMAGA \& TOO, 1987). A dilatação do átrio direito pode ser observada (VAN BIERVLIET et al., 2006) juntamente com a infiltração da parede atrial (SCHMITZ \& SEAHORN, 1994) que pode levar à observação de uma massa de ecogenicidade luminal com múltiplos focos hipoecoicos (VAN BIERVLIET et al., 2006).

Apesar dos achados observados, nos casos de linfoma cardíaco o diagnóstico definitivo é feito com a identificação de células neoplásicas por citopatologia ou hitopatologia (BUCZINSKI et al., 2010).

\section{d) Defeito do septo interventricular}

O defeito do septo interventricular é a afecção cardíaca congênita mais comum em bovinos caracterizada por defeito da porção membranosa do septo interventricular que permite a auscultação de um murmúrio holosistólico de intensidade máxima do lado direito (BUCZINSKI, 2008).

No exame ecocardiográfico os achados são compatíveis com defeito septal na parte membranosa do septo interventricular (Buczinski, Fecteau et al. 2006) (Figura 12). O exame com o modo Doppler é eficiente para estabelecer o diagnóstico e o prognóstico em cavalos (REEF, 2002), contudo em bovinos as informações sobre o prognóstico ainda são escassas. No entanto, a direção do fluxo de sangue pelo defeito é importante para suspeitar de um shunt associado à hipertensão pulmonar, que tem prognóstico ruim (GAVAGHAN et al., 2001).

Além do modo Doppler, a direção do sangue pelo defeito também pode ser avaliada por meio da ecocardiografia com contraste que irá aumentar a ecogenicidade do sangue no coração direito, o que ajuda a ver se o sangue no coração direito pode ser encontrado nas câmaras do coração esquerdo (shunt intracardíaco da direita para a esquerda) (BONAGURA \& PIPERS, 1983).

Outros achados ecocardiográficos encontrados nestas enfermidades são a dilatação do átrio esquerdo, ventrículo esquerdo, ventrículo direito e da artéria pulmonar (Reef, 2002). Outras anomalias congênitas incomuns também foram diagnosticadas pela ecocardiografia como a tetralogia de Fallot, dextroposição da aorta e hipertrofia ventricular direita. (HAGIO et al., 1987).

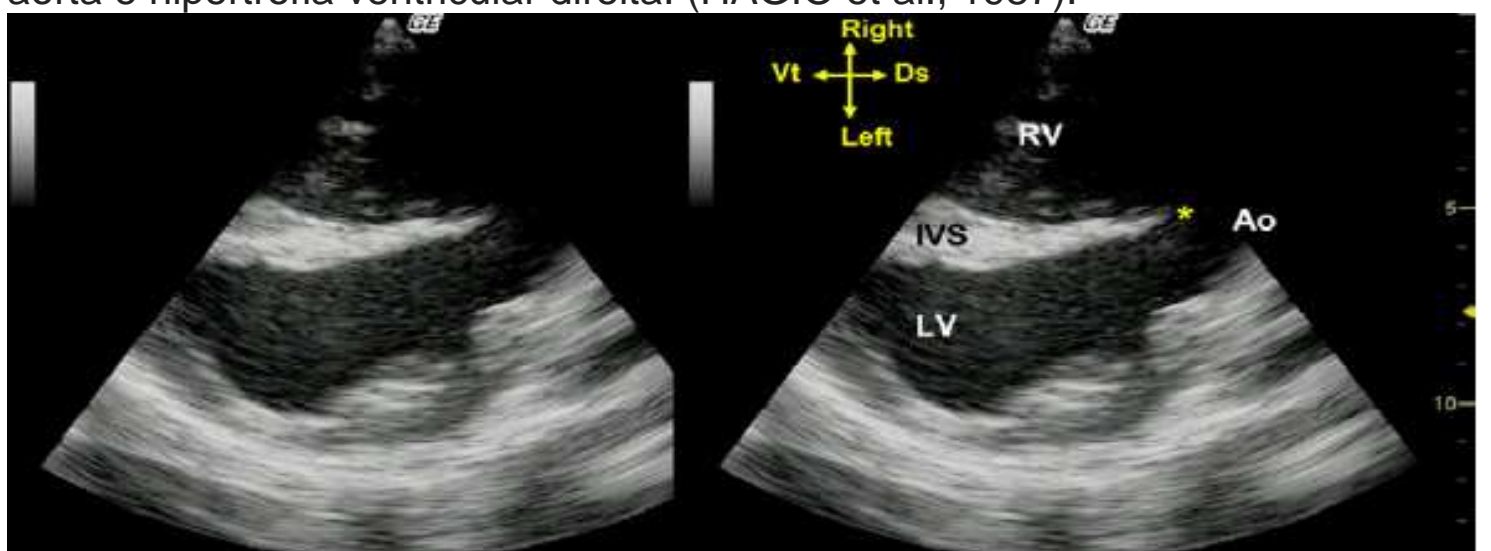

FIGURA 12 - Corte longitudinal do coração de um bezerro pelo lado direito com defeito de septo interventricular. * (parte membranosa do septo interventricular que está faltando), Ao (aorta), Ds (dorsal), IVS (septo interventricular), LV (ventrículo esquerdo), RV (ventrículo direito), Vt (ventral), Right (direito), Left (esquerdo).

Fonte: BUCZINSKI, 2009 
e) Intoxicações

Há relatos do uso da ecocardiografia como ferramenta auxiliar no diagnóstico de enfermidades de origem tóxica como nos estudos realizados para determinar a intoxicação em bezerros pela doxiciclina (BRIHOUM et al., 2010; PEIXOTO et al., 2010; BRIHOUM et al., 2011).

A doxiciclina é antibiótico de largo espectro, eficaz para o tratamento de doenças respiratórias em bezerros. Entretanto vários casos graves de intoxicação foram relatados em bezerros de duas a 16 semanas de idade após a ingestão de doses elevadas deste fármaco (MC EWEN et al., 2002). Os achados clínicos apresentados por estes animais incluem depressão, dispneia, tosse, paresia ou paralisia da língua associada à disfagia e sialorreia, taquicardia, arritmias, taquipneia e sinais de miopatia (BRIHOUM et al., 2010). O exame ecocardiográfico no modo Doppler revelou diminuição global na função sistólica esquerda em bovinos intoxicados com altas doses deste fármaco. Contudo em administração experimental da doxiciclina nas dose de $5 \mathrm{mg} / \mathrm{kg}$ e $25 \mathrm{mg} / \mathrm{kg}$ por via oral em bezerros, não foi possível verificar estas alterações ecocardiográficas (BRIHOUM et al. 2011).

Outro estudo experimental avaliou as alterações ecocardiográficas apresentadas por ovinos intoxicados pelo ácido monofluorocetato de sódio (MF) nas doses únicas de 0,5 e 1,0 mg/kg (cada dose para dois animais) e em doses subletais repetidas diariamente de 0,1 e $0,2 \mathrm{mg} / \mathrm{kg} /$ dia (PEIXOTO et al. 2010).

O MF é o principio tóxico da planta Palicourea marcgravii, causadora de elevado prejuízo na pecuária brasileira (TOKARNIA, 2012). A ação tóxica deste composto se dá sobre o sistema nervoso e principalmente no sistema cardiovascular em ovinos e bovinos. O MF age bloqueando o ciclo de Krebs que causará diminuição da produção de ATP e o acúmulo de citrato no organismo ocasionando efeitos cardiotóxicos e neurotóxicos nos animais intoxicados (NOGUEIRA et al. 2010). Em geral, estes ovinos apresentaram leve aumento de tamanho do átrio esquerdo e direito, bem como das dimensões do ventrículo direito e um dos animais apresentou marcada redução da fração de encurtamento sistólico do ventrículo esquerdo (PEIXOTO et al. 2010). Estas avaliações podem ser reproduzidas em bovinos que apresentam alterações semelhantes aos ovinos quando intoxicados pelo MF.

Bovinos intoxicados experimentalmente por P.marcgravii e tratados com tiossulfato de sódio também foram analisados por meio de exames ecocardiográficos, podendo ser observados o aumento da espessura do septo interventricular na diástole, redução da fração de ejeção e de encurtamento sistólico, além de acentuada redução do débito cardíaco. As alterações relatadas foram observadas nos animais intoxicados e nos tratados com tiossulfato de sódio (RODRIGUES, 2015)

\section{CONSIDERAÇÕES FINAIS E PERSPECTIVAS FUTURAS}

A ecocardiografia é um exame complementar com elevada aplicabilidade na clínica de bovinos, para diagnóstico de cardiopatias, porém é necessário mais estudos que permitam a obtenção completa de informações sobre os valores de normalidade e patológicos dessa espécie.

Algumas dificuldades podem ser encontradas durante a execução deste exame em bovinos como o estreito espaço intercostal, a posição cranial do coração no tórax e o temperamento do animal, contudo estas dificuldades podem ser superadas pelo treinamento da equipe e manejo adequado dos animais . 
As pesquisas que visam estabelecer os parâmetros de normalidade dos aspectos qualitativos, medidas quantitativas e os índices cardíacos para as diversas raças de bovinos em diferentes idades devem ser intensificadas, fornecendo informações que ajudem os veterinários cardiologistas na clínica buiátrica.

\section{REFERÊNCIAS}

AMORY, H.; KAFIDI, N.; LEKEUX, P. Echocardiographic evaluation of cardiac morphologic and functional variables in double-muscled calves. American journal of veterinary research, v. 53, n 9, p. 1540, 1992.

ANAVEKAR, N. S.; OH J. K. Doppler echocardiography: A contemporary review. Journal of Cardiology, v. 54, n 3, p. 347-358, 2009.

BATCHELDER, C. A., WHITCOMB, M. B., BERTOLINI, M., MASON, J. B., PETKOV, S. G., HOFFERT, K. A., ... \& ANDERSON, G. B. Neonatal physiological status of cloned and control calves. Reproduction, Fertility and Development, v. 18, n. 2, p. 120-120, 2005.

BEXIGA, R. A., mateus, A., PhILBey, A. W., ElLis, K., BARRetT, D. C., \& MELLOR, D. J. Clinicopathological presentation of cardiac disease in cattle and its impact on decision making. Veterinary record, v. 162, n. 18, p. 575-580, 2008.

BONAGURA, J.; PIPERS F. Diagnosis of cardiac lesions by contrast echocardiography. Journal of the American Veterinary Medical Association, v. 182, n. 4, p. 396, 1983.

BOON, J. A. Veterinary echocardiography, John Wiley \& Sons, 2011, 2 ed.

BRAUN, U. B. Traumatic pericarditis in cattle: clinical, radiographic and ultrasonographic findings. The Veterinary Journal, v. 182, n. 2, p. 176-186, 2009.

BRAUN, LEJEUNE, RAUCH, GORBER, \& SCHWEIZER. Sonographische Befunde bei 22 Rindern mit Pericarditis traumatica. Schweizer Archiv für Tierheilkunde, v. 150, n. 6 , p. 281-286, 2008.

BRAUN, U. B.; SCHWEIZER, T.; PUSTERLA, N. Echocardiography of the normal bovine heart: technique and ultrasonographic appearance. Veterinary Record, v. 148, n. 2, p. 47-51, 2001.

BRIHOUM, M., AMORY, H., DESMECHT, D., CASSART, D., DELEUZE, S., \& ROLLIN, F. Descriptive Study of 32 Cases of Doxycycline-Overdosed Calves. Journal of Veterinary Internal Medicine, v. 24, n. 5, p. 1203-1210, 2010.

BRIHOUM, M., ROLLIN, F., DESMECHT, D., DETILLEUX, J., \& AMORY, H. Clinical evaluation of cardiac effects of experimental doxycycline overdosing in healthy calves. BMC veterinary research, v. 7, n. 1, p. 40, 2011.

BUCZINSKI, S. Examen échographique de l'appareil cardiovasculaire chez le bovin. Bull. Soc. Vét. Prat. de France, v. 92, n. 2, 2008. 
BUCZINSKI, S. Cardiovascular ultrasonography in cattle. Veterinary Clinics of North America: Food Animal Practice, v. 25, n. 3, p. 611-632, 2009.

BUCZINSKI, S.; FECTEAU, G.; DIFRUSCIA, R. Ventricular septal defects in cattle: A retrospective study of 25 cases. The Canadian Veterinary Journal, v .47, n. 3, p. 246, 2006.

BUCZINSKI, S., FRANCOZ, D., FECTEAU, G., \& DIFRUSCIA, R. The Canadian Veterinary Journal, v. 51, n. 10, p. 1123, 2010.

BUCZINSKI, S.; REZAKHANI, A.; BOERBOOM, D. Heart disease in cattle: diagnosis, therapeutic approaches and prognosis. The Veterinary Journal, v. 184, n. 3, p. 258-263, 2010.

CASTRO, R. 2012 . Ultra-Som. Disponível em http://www.ebah.com.br/content/ABAAAejJsAC/ultra-som. Acesso em 08/10/2013

DARKE, P. G., BONAGURA, J. D., \& KELLY, D. F. Atlas ilustrado de cardiologia veterinária, Manole. 2000.

FIRSHMAN, A. M., SAGE, A. M., VALBERG, S. J., KAESE, H. J., HUNT, L., KENNEY, D., ... \& MURPHY, M. J. Idiopathic hemorrhagic pericardial effusion in cows. Journal of veterinary internal medicine, v. 20, n. 6, p. 1499-1502, 2006.

GAVAGHAN, B.; KITTLESON, M.; DECOCK, H. Eisenmenger's complex in a Holstein-Friesian cow. Australian veterinary journal, v. 79, n. 1, p. 37-40, 2001.

GOWDA, R. M., KHAN, I. A., VASAVADA, B. C., SACCHI, T. J., \& PATEL, R. History of the evolution of echocardiography. International Journal of Cardiology, v. 97, n. 1, p. 1-6, 2004.

HAGIO, M.; MURAKAMI, T.; OTSUKA, H. Two-dimensional echocardiographic diagnosis of bovine congenital heart disease: echocardiographic and anatomic correlations. Japanese Journal of Veterinary Science, v. 49, 1987.

HALLOWELL, G.; POTTER, T.; BOWEN, I. Methods and normal values for echocardiography in adult dairy cattle. Journal of veterinary cardiology, v. 9. N. 2, p. 91-98, 2007.

HEALY, A. M. Endocarditis in cattle: a review of 22 cases. Irish Vet J, v. 49, n. 1, p. 43-48, 1996.

JESTY, S. A., SWEENEY, R. W., DOLENTE, B. A., \& REEF, V. B Idiopathic pericarditis and cardiac tamponade in two cows. Journal of the American Veterinary Medical Association, v. 226, n. 9, p. 1555-1558, 2005.

LITTLE, W. C.; FREEMAN, G. L. Pericardial disease. Circulation, v. 113, n. 12, p. 1622-1632, 2006. 
MC EWEN, B., LUSIS, P., ARCHAMBAULT, M., \& VAN DREUMEL, T. Doxycycline cardiotoxicity in veal calves. AHL Newsletter, v. 6, n. 5, p. 2002.

MICHIMA, L. E., LEAL, M. L., BERTAGNON, H. G., FERNANDES, W. R., \& BENESI, F. J. Avaliação ecocardiográfica em bezerros da raça Holandesa. Pesquisa Veterinária Brasileira, Seropédica, v. 27, n. 12, p. 481-486, 2007.

NOGUEIRA, V. A., FRANÇA, T. N., PEIXOTO, T. C., CALDAS, S. A., ARMiÉN, A. G., \& PEIXOTO, P. V. Intoxicação experimental por monofluoracetato de sódio em bovinos: aspectos clínicos e patológicos. Pesq. Vet. Bras, v. 30, n. 7, p. 533-540, 2010.

OYAMA, M. A. Advances in echocardiography. Veterinary Clinics of North America: Small Animal Practice, v 34, n. 5, p. 1083-1104, 2004.

PEIXOto, T. C., NOGUeIRA, V. A., COELhO, C. D., VEIGA, C. C., PEIXOTO, P. V., \& BRITO, M. F. Avaliações clínico-patológicas e laboratoriais da intoxicação experimental por monofluoroacetato de sódio em ovinos. Pesquisa Veterinária Brasileira, Seropédica, v. 30, n. 12, p. 1021-1030, 2010.

PIPERS, F. H., R. Echocardiography in the horse. JAVMA, v. 170, p. 815, 1977.

POGLIANI, F. C. Parâmetros ecodopplercardiográficos de bezerros da raça Nelore originados através de transferência nuclear de células somáticas adultas-Clonagem, Universidade de São Paulo (USP). Faculdade de Medicina Veterinária e Zootecnia, p. 98, 2010.

REEF VB, M. S. Diseases of the cardiovascular system. Large animal internal medicine. S. BP, St. Louis, Mosby: 443-478. 2002).

RODRIGUES, M. K. F. Tratamento com tiossulfato de sódio em bovinos intoxicados experimentalmente pela palicourea marcgravii a. St hil. Goiânia: Universidade Federal de Goiás; 2015.

SCHMITZ, D.; SEAHORN, T. Use of echocardiography to detect tumors in the heart of a bull with bovine leukosis. Journal of the American Veterinary Medical Association, v. 205, n. 11, p. 1590, 1994.

SCHWEIZER, T.; SYDLER, T.; BRAUN, U. Kardiomyopathie, Endokarditis valvularis thromboticans und Perikarditis traumatica beim Rind-Klinische und echokardiographische Befunde an drei Fallberichten. Schweizer Archiv für Tierheilkunde, v. 145, n. 9, p. 425-430, 2003.

SOUZA, M. C. Princípios da Ecocardiografia Veterinária. Universisdade Federaldo Tocantins, p. 10, 2010.

TOKARNIA, C. H. Plantas tóxicas do Brasil para animais de produção, Ed. Helianthus, 2012.

VAN BIERVLIET, J., KRAUS, M., WOODIE, B., DIVERS, T. J., GELZER, A., \& AINSWORTH, D. Thoracoscopic pericardiotomy as a palliative treatment in a cow 
with pericardial lymphoma. Journal of Veterinary Cardiology, v. 8, n. 1, p. 69-73, 2006.

WORTH, L.; REEF, V. Pericarditis in horses: 18 cases (1986-1995). Journal of the American Veterinary Medical Association, v. 212, n. 2, p. 248-253, 1998.

YAMAGA, Y.; TOO, K. Diagnostic ultrasound imaging of vegetative valvular endocarditis in cattle. Japanese Journal of Veterinary Research, v. 35, n. 1, p. 4963, 1987.

ZARIFI, M., BUCZINSKI, S., REZAKHANI, A., DEZFOULI, M. R. M., \& KHONSHA, A. Effect of lactation on functional and morphological echocardiographic variables in adult dairy cows. Journal of Veterinary Cardiology, v. 14, n. 3, p. 415-421, 2012.

ZDRAVKOVIĆ, M., DELJANIN-ILIĆ, M., MILINIĆ, N., \& ZDRAVKOVIĆ, D. A historical perspective of tissue Doppler - when the starlight illuminates the myocardial function. Medicinski pregled, v. 59, n.1-2, p. 85, 2006. 